\title{
Impact of Weather Parameters and Population Density on the COVID-19 Transmission: Evidence from 81 Provinces of Turkey
}

\author{
Mervan Selcuk $^{1} \cdot$ Sakir Gormus ${ }^{2} \cdot$ Murat Guven $^{3}$
}

Received: 5 November 2020 / Accepted: 20 December 2020 / Published online: 13 January 2021

(c) King Abdulaziz University and Springer Nature Switzerland AG 2021

\begin{abstract}
Weather factors are effective to transmission of various diseases. Middle East Respiratory Syndrome (MERS), Severe Acute Respiratory Syndrome (SARS), and kinds of influenza can be given as example these diseases. The novel corona virus which is called COVID-19 is the most dangerous problem all around the world in these days. Early studies have revealed that COVID-19 cases are affected by environmental factors. Therefore, the purpose of this paper is to examine the relationship between the number of novel coronavirus cases and several weather parameters in 81 provinces of Turkey. Mean incubation period of COVID-19 is in question. Thus, this paper also aims to provide better understanding of the exact incubation period in Turkey by employing four different timeframe which are on the day (lag 0), 3 days ago (lag 3), 7 days ago (lag 7) and 14 days ago (lag 14). We have considered population density as a control variable. The dataset cover COVID-19 cases, population density, average temperature, humidity, pressure, dew point, wind speed, and sunshine duration for 81 provinces of Turkey. We find that population density has a positive correlation with COVID-19 cases. We also find that in lag 3, all parameters except for sunshine duration are negatively correlated with COVID-19 cases and significant. However, only 3 parameters, temperature, air pressure and dew point are negatively correlated with COVID-19 cases and significant for lag 0, lag 7 and lag 14. In addition, temperature, air pressure and dew point parameters are negative and significant in all timeframes.
\end{abstract}

Keywords COVID-19 $\cdot$ Environment health $\cdot$ Turkey $\cdot$ Weather $\cdot$ Population density

\section{Introduction}

The world health organization (WHO) announced on 31 December 2019 that a novel type of pneumonia was detected in Wuhan, China (WHO 2019a; b). After this date, the world

Sakir Gormus

sgormus@sakarya.edu.tr

Mervan Selcuk

mervanselcuk@sakarya.edu.tr

Murat Guven

muratguven@sakarya.edu.tr

1 Research Center for Islamic Economics and Finance, Sakarya University, Esentepe Campus, Serdivan, Sakarya, Turkey

2 Department of Public Finance, Faculty of Political Sciences, Sakarya University, Esentepe Kampüsü, 54050 Serdivan, Sakarya, Turkey

3 Department of Statistics, Faculty of Arts and Sciences, Sakarya University, Esentepe Campus, Serdivan, Sakarya, Turkey has been dealing with a virus pandemic that will be among the worst examples it has ever experienced before. This virus spread all over the world and has become the most important problem of today, since the first case was seen in Wuhan.

Coronaviruses are a kind of related RNA viruses and were detected many different types which are well known worldwide. It causes respiratory infections and other dangerous illness like SARS, MERS, or COVID-19 (HewingsMartin 2020). A newly identified coronavirus which is called COVID-19 in Wuhan has caused a worldwide pandemic of respiratory illness.

The development of transportation opportunities in the twenty-first century has facilitated the spread of infectious diseases all over the world. SARS-CoV was outbreak in 2002 and the first cases were detected in China. SARS-CoV spread rapidly and this disease was detected in many countries. It was transmitted to more than 8000 people and nearly 1000 people died due to this disease (WHO 2020).

MERS-CoV epidemic first appeared in Saudi Arabia in 2012. The MERS epidemic was more deadly than the SARS outbreak. MERS infected more than 2000 people, causing up 


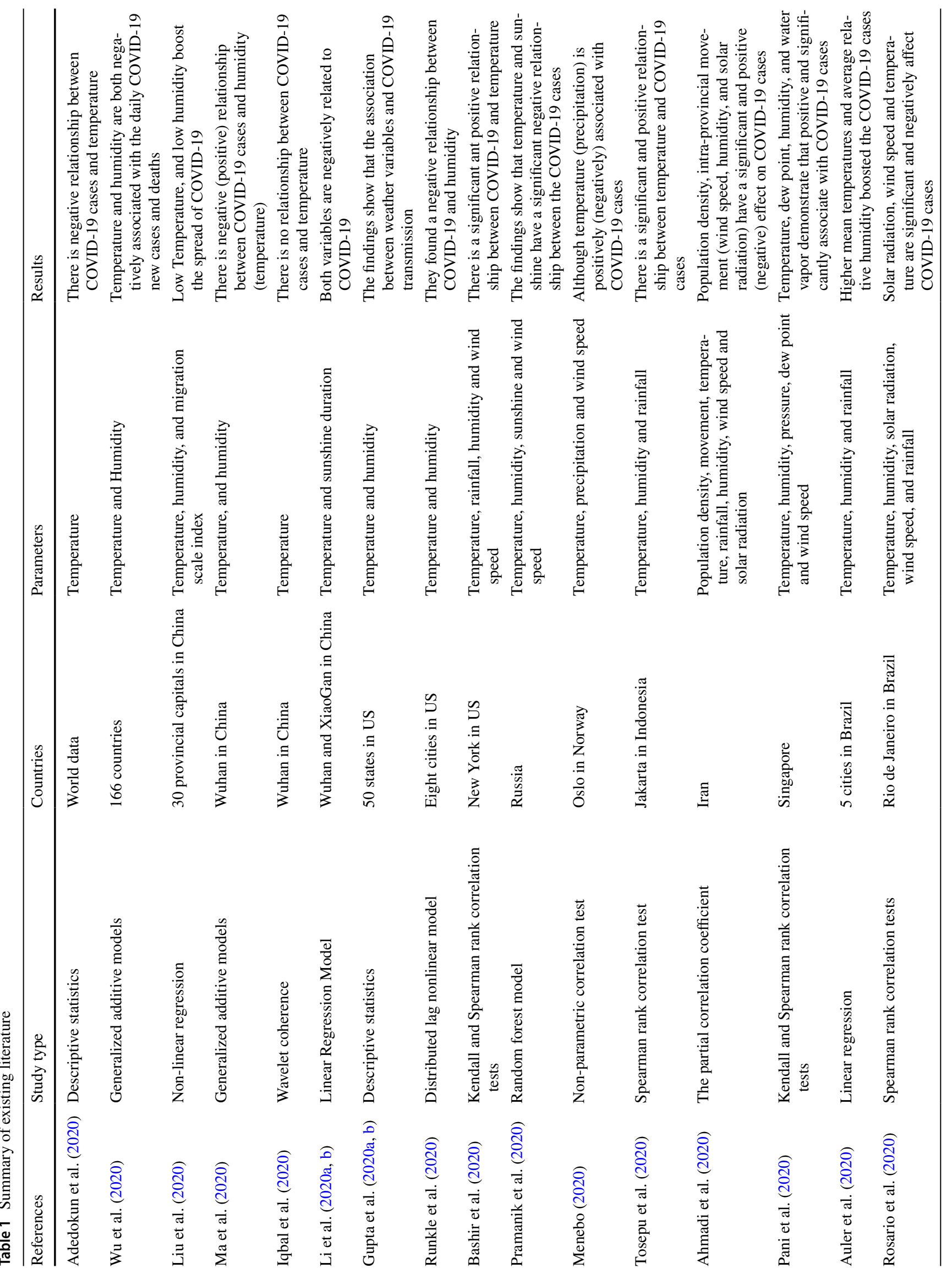


to 900 deaths (WHO 2019a). After these epidemics, a novel corona virus was detected in China at the end of 2019 which is named COVID-19. It is also a kind of corona virus. As in previous corona viruses, COVID-19 also has same mode of transmissions such as via droplets, sneezing or breathing. Common symptoms of COVID-19 appear within 14 days but mean incubation period of corona viruses approximately 5-6 days (Lauer et al. 2020).

The first centre of the pandemic was China, but the disease has spread all over the world, and the new centre of the pandemic is the USA, Brazil and India which have number of confirmed cases 4 million, 2.2 million and 1.3 million, respectively. Total confirmed cases all over the world are 15.2 million and number of global deaths are 624 thousand. The first confirmed COVID-19 case was detected in Turkey on 11th March. Nearly 230 thousand COVID-19 cases and more than 5.5 thousand deaths were recorded as the end of July 2020. (Johns Hopkins University 2020).

Even though the transmission speed of COVID-19 is faster than SARS and MERS, the death rate of COVID19 is less than SARS and MERS. COVID-19 continues to transmission worldwide, and a second wave of COVID-19 is expected to be appeared in cold temperature. Following the emergence of the COVID-19 pandemic, the health institutions of the countries are sharing statistical data on the spread of this virus. Researchers have done a lot of studies to determine which factors affect to transmission of COVID19 by evaluating these data together with various parameters. The weather variables are good indicators to forecast COVID-19 cases in following days (Gupta et al. 2020a, b; Li et al. 2020a, b; Rohrer et al. 2020; Wu et al. 2020). Table 1 shows the results of existing literature.

Numbers of early studies were investigated the relationships between weather parameters, population density and COVID-19 cases. Iqbal et al. (2020), Liu et al. (2020), Ma et al. (2020), Shi et al. (2020) have studied these variables for China which is the first centre of the pandemic. Bashir et al. (2020), Gupta et al. (2020a, b), Runkle et al. (2020) have focused on US and they have employed similar variables.

Liu et al. (2020) have examined the relationships between COVID-19 cases and meteorological parameters in 30 provincial capital cities of China. The dataset covers number of confirmed cases, ambient temperature (AT), diurnal temperature range (DTR), absolute humidity (AH) and migration scale index (MSI) for selected cities between January 20th and March 2nd, 2020. The findings demonstrate that low temperature, mild diurnal temperature range and low humidity boost the spread of COVID-19. Shi et al. (2020) also examined how temperature has relationship with COVID19 cases in 30 provinces in China between January 20 and February 29, 2020. COVID-19 cases decreased slowly with higher temperatures. 
Table 2 Abbreviations of variables

\begin{tabular}{|c|c|}
\hline Abbreviations & Description \\
\hline Density & $\begin{array}{l}\text { Population density (people per } \\
\text { sq. km of land area) }\end{array}$ \\
\hline Temperature & Daily average temperature $\left({ }^{\circ} \mathrm{C}\right)$ \\
\hline Dew point & Daily average dew point $\left({ }^{\circ} \mathrm{C}\right)$ \\
\hline Humidity & Daily average humidity (\%) \\
\hline Pressure & Daily average air pressure $(\mathrm{hPa})$ \\
\hline Wind speed & Average wind speed $(\mathrm{m} / \mathrm{s})$ \\
\hline Sunshine duration & Daily sunshine duration (hour) \\
\hline Lag 0 & 0 days ago, 1 April 2020 \\
\hline Lag 3 & 3 days ago, 29 March 2020 \\
\hline Lag 7 & 7 days ago, 25 March 2020 \\
\hline Lag 14 & 14 days ago, 18 March 2020 \\
\hline
\end{tabular}

The relationships between COVID-19 caused deaths and weather parameters were investigated by Ma et al. (2020) in period of 20 January-29 February 2020 in Wuhan, China. The findings demonstrate that a positive relationship with COVID-19 daily death counts was observed for diurnal temperature range, but negative relationships for relative humidity. Iqbal et al. (2020) aim to investigate the relationships between temperature and new COVID-19 cases in Wuhan in period of 21 January-31 March 2020 using Wavelet Coherence. They found that the increasing temperature is not important to slow down COVID-19 cases. This result is contrary to many earlier papers which demonstrate important role of temperature in slowing down the COVID19 transmission. Li et al. (2020a, b) also have examined that the correlation temperature and sunshine duration with COVID-19 cases for China. They found that temperature has significant and negative association with the COVID-19 and sunshine duration is in an inverse correlation.

After the pandemic spread all over the world, the United States has become the country with the highest number of COVID-19 cases. Gupta et al. (2020a, b) investigated the effect of weather parameters on spread of the COVID-19 cases in more populated countries, like India. The dataset covers the daily new cases of COVID-19 cases in 50 states of US in period of 1 January-9 April 2020. The results demonstrate that the association between weather conditions and COVID-19 transmission. The findings can be useful to project Indian provinces which would be weather caused transmission of COVID-19 in approaching months of 2020.
Table 3 Descriptive statistics of variables

\begin{tabular}{|c|c|c|c|c|c|c|}
\hline & Mean & Median & $\operatorname{Max}$ & Min & Standard deviation & Observations \\
\hline Cases & 181.24 & 26 & 8852 & 2 & 985.95 & 81 \\
\hline Density & 132.18 & 64.11 & 2986.77 & 11.39 & 333.32 & 81 \\
\hline Temperature & 8.75 & 8.80 & 17.30 & 1.80 & 3.31 & 81 \\
\hline Temperature_3 & 8.49 & 8.30 & 15.30 & 0.90 & 2.78 & 81 \\
\hline Temperature_7 & 9.32 & 8.90 & 17.60 & 3.90 & 3.04 & 81 \\
\hline Temperature_14 & 3.23 & 3.70 & 15.20 & -6.00 & 4.37 & 81 \\
\hline Dew point & 4.69 & 4.70 & 10.00 & -1.40 & 2.63 & 81 \\
\hline Dew point_3 & 5.18 & 5.60 & 10.90 & -1.50 & 2.70 & 81 \\
\hline Dew point_7 & 4.29 & 4.40 & 10.40 & -1.70 & 2.79 & 81 \\
\hline Dew point_14 & -1.81 & -2.00 & 8.90 & -12.40 & 5.23 & 81 \\
\hline Humidity & 78.24 & 79.60 & 98.30 & 57.00 & 10.16 & 81 \\
\hline Humidity_3 & 82.16 & 83.20 & 98.80 & 53.70 & 9.17 & 81 \\
\hline Humidity_7 & 73.57 & 73.60 & 96.00 & 50.30 & 10.2 & 81 \\
\hline Humidity_14 & 72.48 & 73.10 & 97.10 & 23.40 & 17.82 & 81 \\
\hline Pressure & 933.38 & 926.80 & 1017.70 & 813.20 & 61.88 & 81 \\
\hline Pressure_3 & 929.29 & 920.00 & 1010.50 & 808.60 & 61.41 & 81 \\
\hline Pressure_7 & 937.59 & 931.00 & 1022.40 & 817.90 & 62.36 & 81 \\
\hline Pressure_14 & 937.32 & 931.10 & 1027.00 & 812.60 & 65.13 & 81 \\
\hline Wind speed & 2.01 & 1.70 & 6 & 0.60 & 1.11 & 81 \\
\hline Wind speed_3 & 1.82 & 1.70 & 5.80 & 0.50 & 0.92 & 81 \\
\hline Wind speed_7 & 1.97 & 1.50 & 7.40 & 0.50 & 1.30 & 81 \\
\hline Wind speed_14 & 2.34 & 2 & 9.8 & 0.50 & 1.58 & 81 \\
\hline Sunshine duration & 3.38 & 2.90 & 10.10 & 0 & 3.19 & 81 \\
\hline Sunshine duration_3 & 1.33 & 0.1 & 6.70 & 0 & 1.95 & 81 \\
\hline Sunshine duration_7 & 3.50 & 3.40 & 10 & 0 & 3.42 & 81 \\
\hline Sunshine duration_14 & 2.97 & 0.40 & 11.60 & 0 & 3.89 & 81 \\
\hline
\end{tabular}




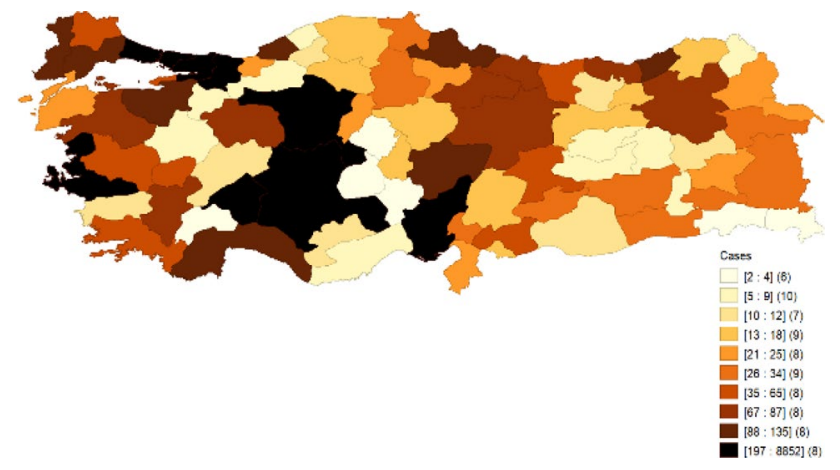

Fig. 1 COVID-19 cases of all provinces of Turkey in the day of lag 0

Runkle et al. (2020) investigated the relationship between COVID-19 cases and meteorological variables for selected 8 cities in US. Empirical results show that humidity was positively related with COVID-19 transmission in 4 cities in short-term. Temperature and solar radiation results did not demonstrate a strong relation with COVID-19 cases. Bashir et al. (2020) studied the relationship between COVID-19 cases and weather parameters in New York City, USA in period of 1 March-12 April 2020. The empirical findings show that average temperature, minimum temperature, and air quality have significantly correlated with the COVID-19 cases.

Pramanik et al. (2020) investigate the relationships between weather parameters and the transmission of COVID-19 in Russia employing the random forest model. The findings show that the effect of temperature and sunshine on the transmission of COVID-19 is a significant and negative relationship. They also observed the effects of diurnal temperature range, wind speed, and relative humidity, on the intensity of the COVID-19 spread. Menebo (2020) has studied that how COVID-19 cases are affected by weather conditions in Oslo, Norway using a non-parametric correlation test in period of February 27-May 2, 2020. The dataset cover temperature, precipitation level and wind speed. Empirical results show that temperature is positively associated with COVID-19 cases. On the other hand, number of infected people are affected negatively from precipitation.

Tosepu et al. (2020) have studied that how COVID-19 cases affected by weather conditions in period of January-March 29, 2020 in Jakarta, Indonesia. Spearman-rank correlation test was employed for the analysis. Only temperature average was significantly associated with COVID-19
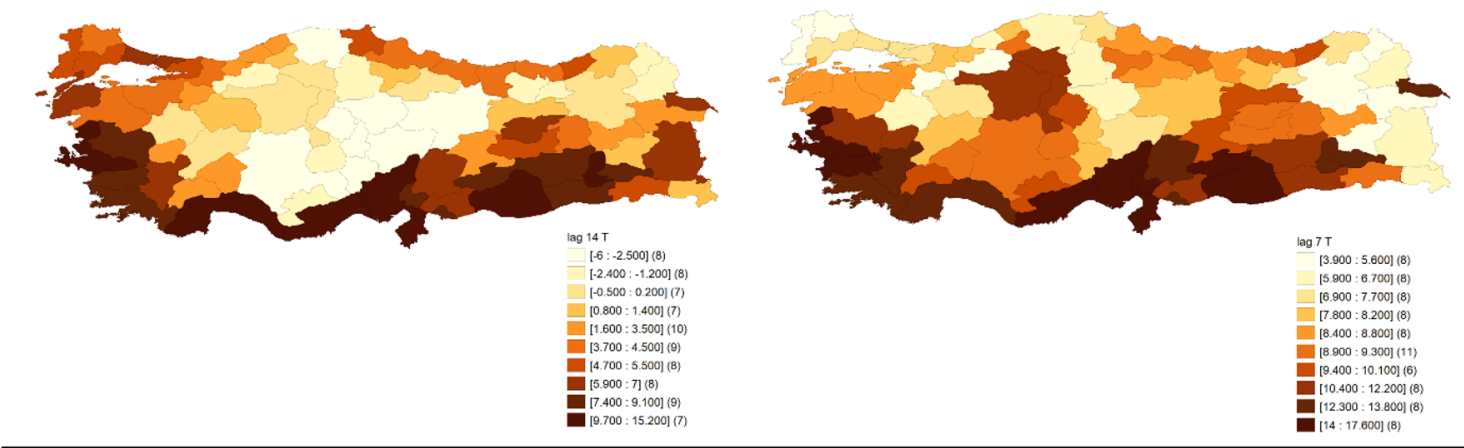

Temperature, Lag 3

Temperature, Lag 0
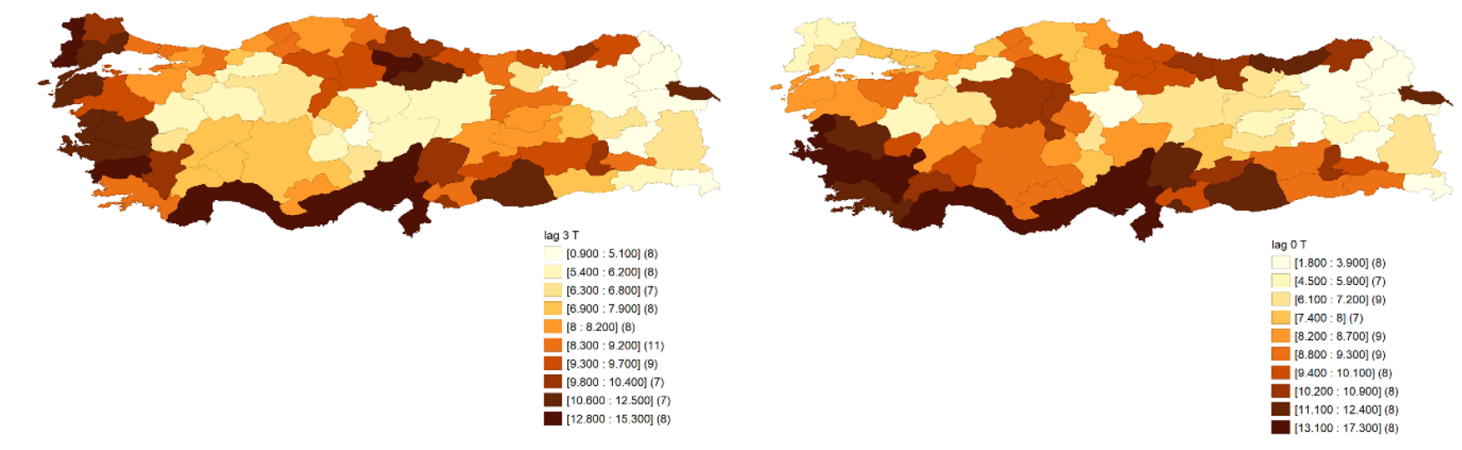

Fig. 2 Temperature of all provinces of Turkey in the day of lag 0, lag 3, lag 7 and lag 14 


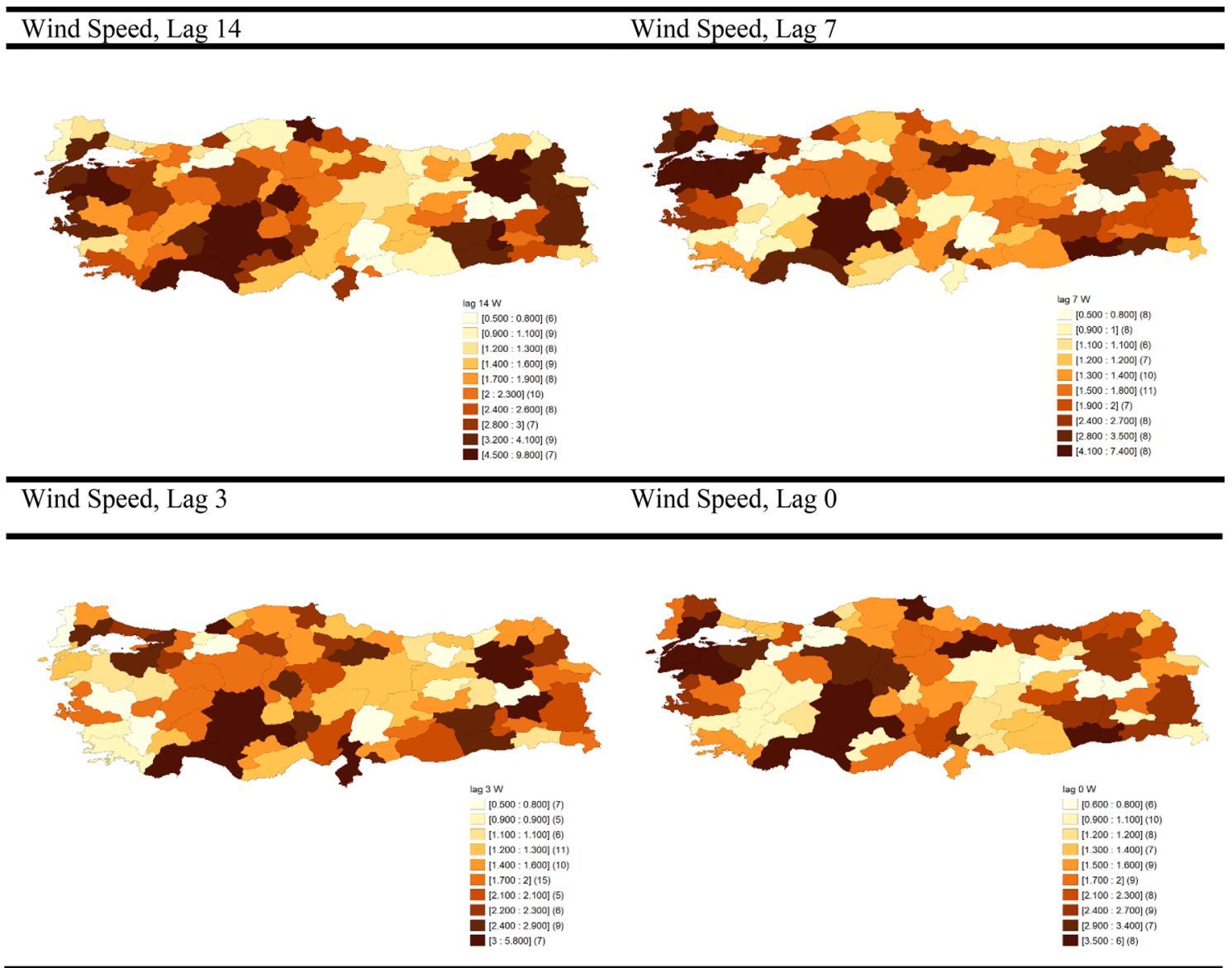

Fig. 3 Wind speed of all provinces of Turkey in the day of lag 0, lag 3, lag 7 and lag 14

pandemic. Ahmadi et al. (2020) examined the relationships between COVID-19 cases and selected weather conditions in Iran. Also, population density, intra-provincial movement, and infection days considered in the study. The results demonstrate that the population density, intra-provincial movement have a direct relation with COVID-19 cases. Unlike provinces with low levels of wind speed, humidity, and solar radiation reveal to a high rate of COVID-19 cases.

Auler et al. (2020) analysed that how meteorological parameters like temperature, humidity and rainfall affect the transmission of COVID-19 in five provinces for Brazil. Empirical result show that temperature and humidity have a positive relationship with COVID-19 cases. This result is also contrary to many earlier papers which demonstrate important role of temperature and humidity in slowing down the COVID-19 transmission. Rosario et al. (2020) investigated that the correlation between weather parameters and COVID-19 cases in the State of Rio de Janeiro, Brazil. The results show that solar radiation has a strong negative relation with the COVID-19 case. In line with the general literature, temperature and wind speed have a negative relationship with the number of infected people.
Pani et al. (2020) examined that the role of Singapore's hot weather conditions in COVID-19 spread by analysing the relationship between meteorological variables and the COVID-19 cases. The result from Spearman and Kendall rank correlation tests show that temperature, dew point, humidity and water vapor demonstrated positive and significant relation with COVID-19 cases. The effects of temperature and humidity on new COVID-19 cases and deaths are examined by Wu et al. (2020) for 166 countries (excluding China) on March 27, 2020. The empirical results show that temperature and humidity were both negatively associated with new COVID-19 cases and deaths. Şahin (2020) studied the relationship between weather parameters and COVID-19 cases for 9 provinces in Turkey using Spearman's correlation coefficients. The findings show that population, wind speed, and temperature associate with COVID-19 cases.

To the best knowledge of authors, there is no study that examines the relationship between weather parameters, population density and the spread of COVID-19 for 81 provinces of Turkey. This study will fill this research gap. Therefore, this paper shows how COVID-19 cases are affected from population density, temperature, humidity, pressure, 


\begin{tabular}{ll}
\hline Air Pressure, Lag 14 & Air Pressure, Lag 7 \\
\hline
\end{tabular}
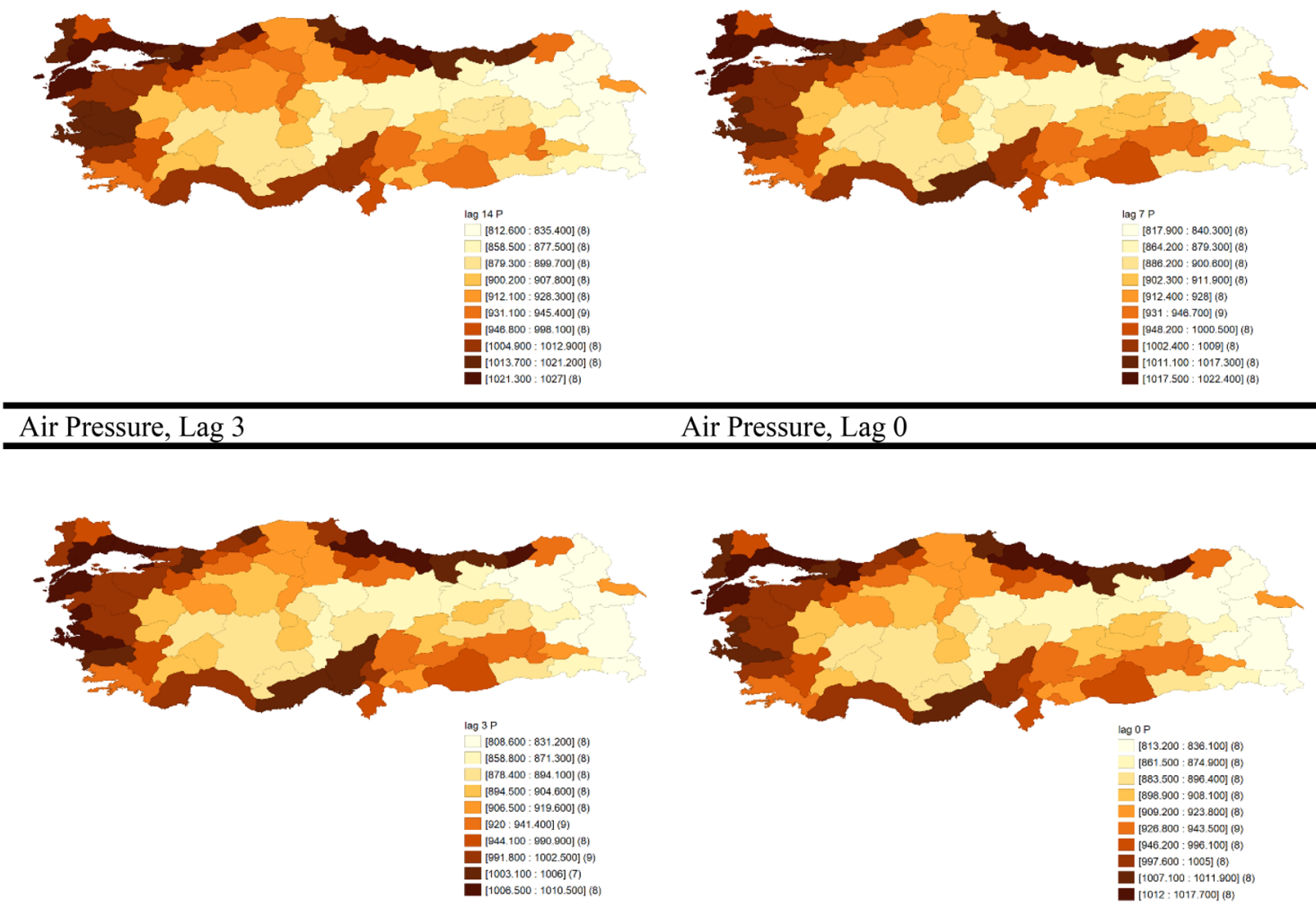

Air Pressure, Lag 0

Fig. 4 Air pressure of all provinces of Turkey in the day of lag 0, lag 3, lag 7 and lag 14

dew point, wind speed, and sunshine duration in 81 cities of Turkey using regression model. The results of the study provide useful information to policymakers when struggling with COVID-19.

In the first part of the paper, we examined the literature and the studies done so far. The relevant literature has shown that our study is unique in terms of topic. The econometric methods and data are stated in the second part. Empirical results are presented in the third section. The discussion and the conclusion are the fourth and the fifth parts of the study, respectively.

\section{Data and Econometric Methods}

\subsection{Data}

The data of COVID-19 case for 1st April 2020 are obtained from the Ministry of Health of Republic of Turkey for 81 provinces of Turkey. However, the data of weather parameters are provided by the Meteorological Department of the Republic of Turkey and the population density data has been taken from the Turkish Statistical Institute. The dataset cover
COVID-19 cases, population density (people per sq. km of land area) and daily weather parameters for 81 provinces of Turkey. Daily weather parameters are average temperature $\left({ }^{\circ} \mathrm{C}\right)$, average humidity $(\%)$, average air pressure $(\mathrm{hPa})$, average dew point $\left({ }^{\circ} \mathrm{C}\right)$, average wind speed $(\mathrm{m} / \mathrm{s})$, and sunshine duration (hour). Abbreviations of variables are listed in Table 2. Because of the different geographical structure of provinces, weather parameters of 81 provinces in Turkey are different.

Researchers have not exact information about COVID19s incubation period. The incubation period is accepted within 14 days when viruses located in body (Lauer et al. 2020). Each weather variable is controlled for 4 timeframes. The timeframes are on the day (lag 0), 3 days ago (lag 3 ), 7 days ago (lag 7) and 14 days ago (lag 14). Hence, this paper aims to provide better understanding of the exact incubation period in Turkey. Table 3 shows that descriptive statistics of variables.

The highest number of COVID-19 cases ( 8852 cases) and population density ( 2986.77 people per sq. $\mathrm{km}$ of land area) in Istanbul. The descriptive statistics of the weather parameters demonstrate that a minimum temperature of $-6^{\circ} \mathrm{C}$ and the highest maximum temperature of $17.6^{\circ} \mathrm{C}$, the lowest 

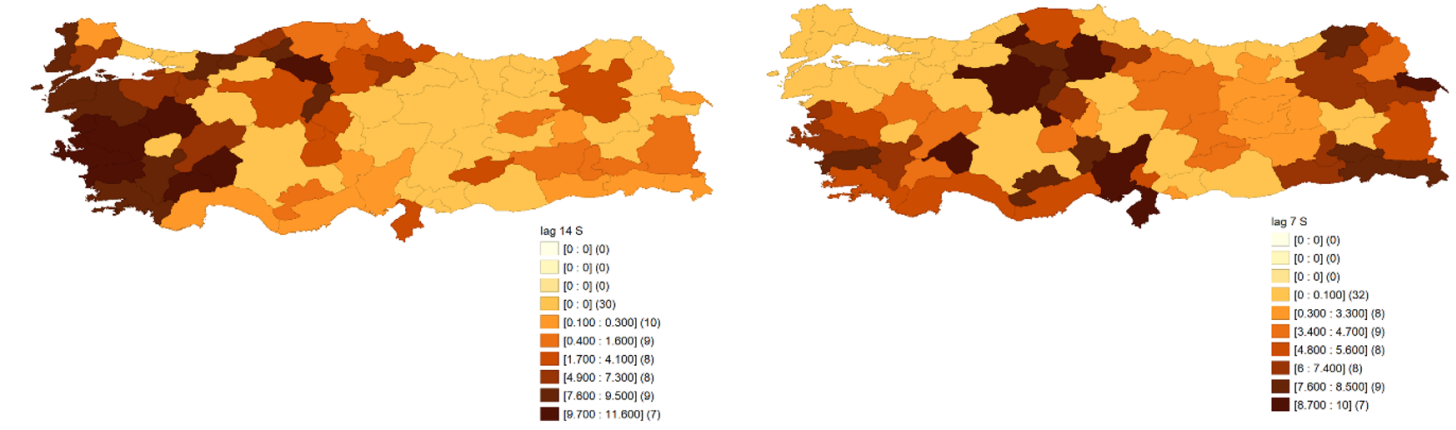

Sunshine Duration, Lag 3

Sunshine Duration, Lag 0
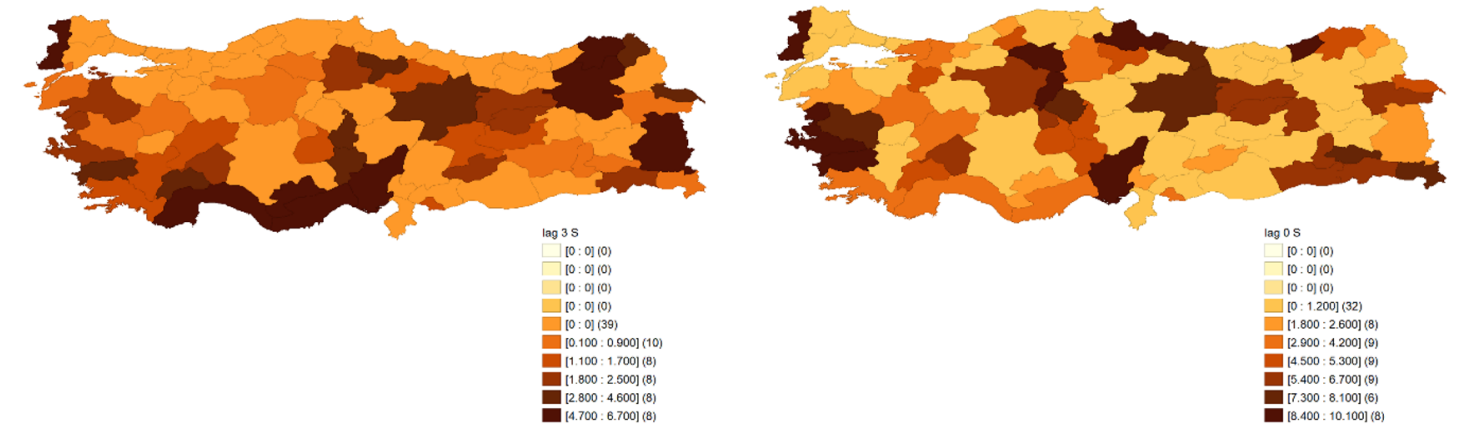

Fig. 5 Sunshine duration of all provinces of Turkey in the day of lag 0, lag 3, lag 7 and lag 14

dew point of $-12.4^{\circ} \mathrm{C}$ and the highest dew point of $10.9^{\circ} \mathrm{C}$, the lowest humidity of $\% 23.4$ and the highest humidity of $\% 98.8$ in the provinces of Turkey. In addition to that, the lowest wind speed was $1.5 \mathrm{~m} / \mathrm{s}$ and highest wind speed was $9.8 \mathrm{~m} / \mathrm{s}$. Figure 1 shows the COVID-19 cases of all provinces of Turkey on 1st April 2020 which is reference date of our study. Figures 2, 3, 4, 5, 6, 7 represent the weather parameters of all provinces of Turkey in the day of lag 14, lag 7, $\operatorname{lag} 3$, and lag 0 , respectively.

\subsection{Econometric Methods}

The relationship between the number of novel coronavirus cases, population density and several weather parameters can be specified as

$C=F(D, W)$

where $\mathrm{C}$ is the number of novel coronavirus cases, $\mathrm{D}$ is the population density, $\mathrm{W}$ are independent variables that are the weather parameters like temperature, wind speed, air pressure, dew point, humidity and sunshine duration. In addition, these weather parameters are considered as lag 0 , lag 3, lag 7 and lag 14.

We can express our regression model as follows:

Model $1: C_{i}=\beta_{0}+\beta_{1} D_{i}+\beta_{2} W_{i_{0}}+\varepsilon_{i}$

Model $2: C_{i}=\beta_{0}+\beta_{1} D_{i}+\beta_{2} W_{i_{3}}+\varepsilon_{i}$

Model $3: C_{i}=\beta_{0}+\beta_{1} D_{i}+\beta_{2} W_{i_{7}}+\varepsilon_{i}$

Model $4: C_{i}=\beta_{0}+\beta_{1} D_{i}+\beta_{2} W_{i_{14}}+\varepsilon_{i}$

In these models, $\mathrm{C}$ is the number of novel coronavirus cases, $\mathrm{D}$ is the population density and $\mathrm{W}$ are the weather parameters that are $W_{i_{0}}, W_{i_{3}}, W_{i_{7}}, W_{i_{14}}$ showing the weather parameter on the day (lag 0 ), weather parameter 3 days ago (lag 3), weather parameter 7 days ago (lag 7) and weather parameter 14 days ago (lag 14), respectively. The subscript $\mathrm{i}$ is the individual and denotes the provinces of Turkey. $\beta_{0}$ and $\varepsilon_{i}$ are intercept and disturbance. $\beta_{1}$ represents the coefficient of $D_{i}$ and $\beta_{2}$ denotes the coefficients of $W_{i_{0}}, W_{i_{3}}, W_{i_{7}}$ and $W_{i_{14}}$. 


\begin{tabular}{ll}
\hline Humidity, Lag 14 & Humidity, Lag 7 \\
\hline
\end{tabular}
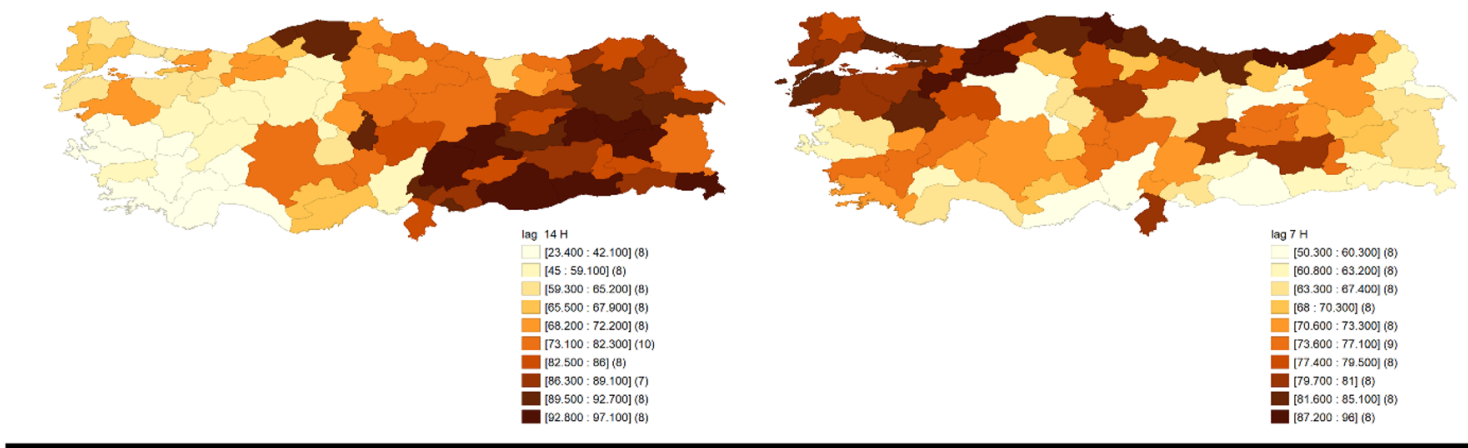

Humidity, Lag 3

Humidity, Lag 0
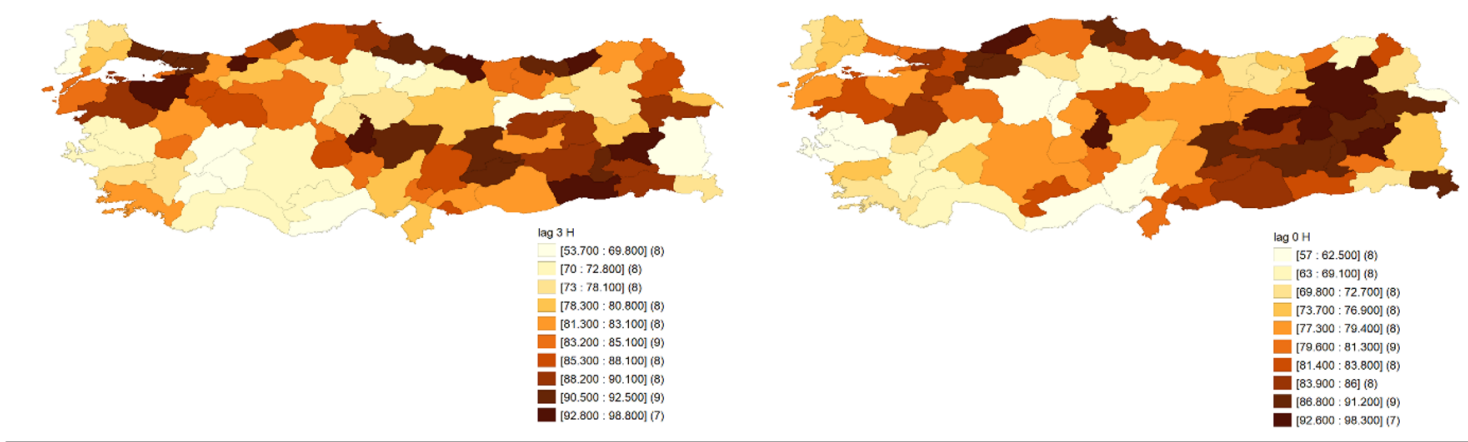

Fig. 6 Humidity of all provinces of Turkey in the day of lag 0, lag 3, lag 7 and lag 14

In this study, we use ordinary least-squares linear regression (OLS) to investigate the effect of the independent variables on dependent variables (Angrist and Pischke 2009). For this purpose, we use four different models depending on different timeframes for each weather parameters. Thus, we test the effect of temperature, wind speed, air pressure, dew point, humidity and sunshine duration with density on novel coronavirus cases in four different models.

\section{Results}

As of April 1st, 2020, a total of 15,679 cases were officially reported in 81 provinces in Turkey. The number of COVID19 cases in the 10 most contaminated cities is account for $83 \%$ of the total number of cases which provinces are the most populated and have the highest population density. The 55 provinces have less than 50 cases. Population density, temperature, dew point, humidity, pressure, wind speed, and sunshine duration are investigated for 4 timeframes which are lag 0 , lag 3 , lag 7 and lag 14 . All population density results similar with each other and all of them are positively correlated with COVID-19 cases and significant as expected.

Table 4 shows the relationship between temperature and the number of total cases for different timeframes in all provinces of Turkey.

In Table 4, we find that temperature variable is negatively correlated with COVID-19 cases and significant in each timeframe as expected. In other words, while the temperature is increasing, the number of COVID-19 cases are decreasing. Table 5 demonstrates the relationship between wind speed and the number of total cases for different timeframes in all provinces of Turkey.

In Table 5, we find that there is a negative and significant relationship between wind speed and COVID-19 cases only in lag 3. Table 6 shows the relationship between air pressure and the number of total cases. Table 7 demonstrates the relationship between dew point and the number of total cases for different timeframes in all provinces of Turkey.

The results from Tables 5 and 6 show that air pressure and dew point variables are significant and negatively correlated with COVID-19 cases in each timeframe as expected.

Table 8 shows the relationship between humidity and the number of total cases. Table 9 demonstrates the relationship 


\begin{tabular}{ll}
\hline Dew Point, Lag 14 & Dew Point, Lag 7 \\
\hline
\end{tabular}
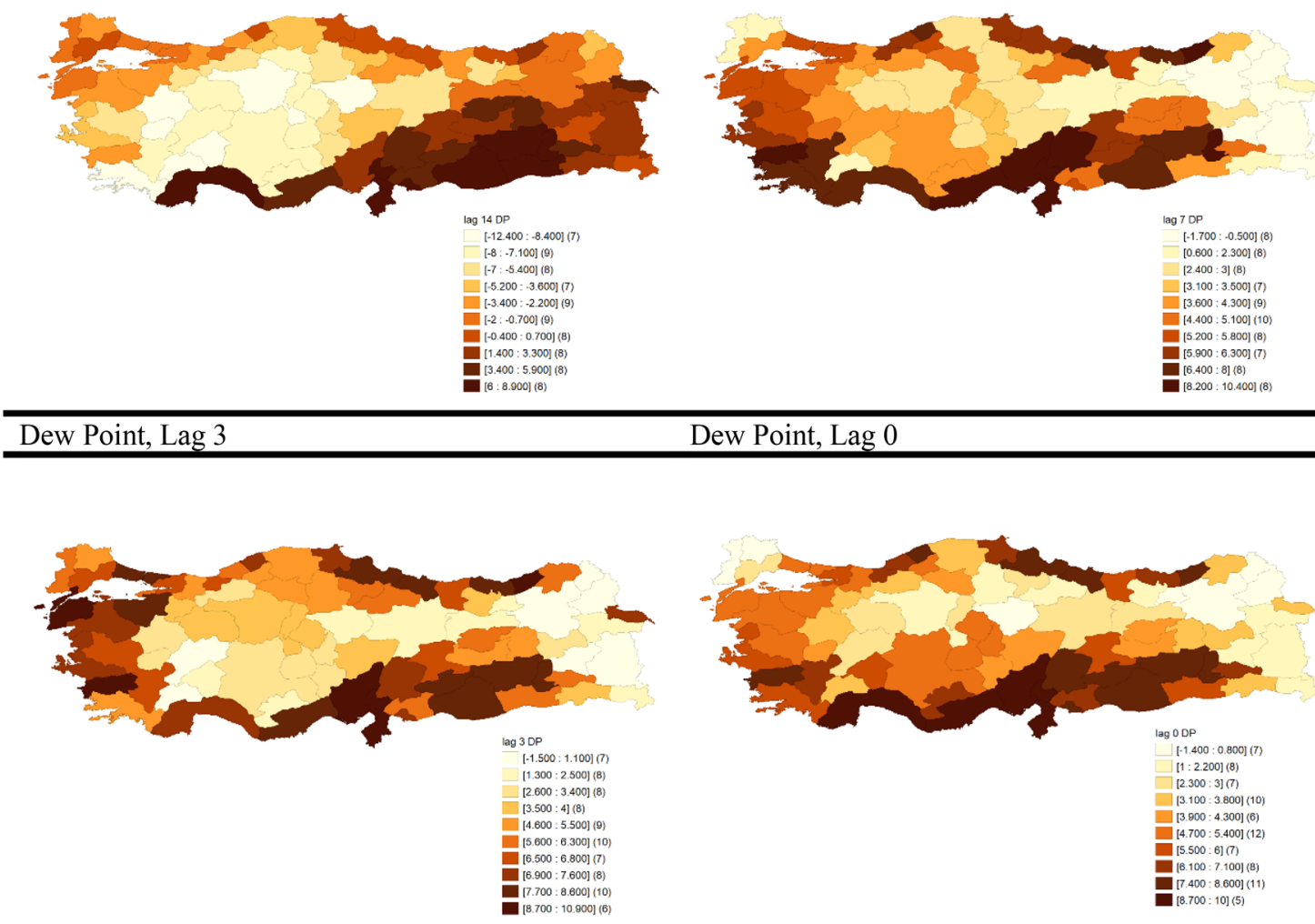

Fig. 7 Dew point of all provinces of Turkey in the day of lag 0, lag 3, lag 7 and lag 14

Table 4 OLS Results of temperature models

\begin{tabular}{|c|c|c|c|c|}
\hline & Model 1 & Model 2 & Model 3 & Model 4 \\
\hline Density & $\begin{array}{l}2.894 * * * \\
{[0.072]}\end{array}$ & $\begin{array}{l}2.903 * * * \\
{[0.073]}\end{array}$ & $\begin{array}{l}2.884 * * * \\
{[0.073]}\end{array}$ & $\begin{array}{l}2.934 * * * \\
{[0.069]}\end{array}$ \\
\hline Temperature & $\begin{array}{l}-20.909 * * * \\
{[7.334]}\end{array}$ & & & \\
\hline Temperature_3 & & $\begin{array}{l}-24.413 * * * \\
{[8.781]}\end{array}$ & & \\
\hline Temperature_7 & & & $\begin{array}{l}-20.385^{* *} \\
{[8.033]}\end{array}$ & \\
\hline Temperature_14 & & & & $\begin{array}{l}-22.803 * * * \\
{[5.329]}\end{array}$ \\
\hline Constant & $\begin{array}{l}-18.379 \\
{[68.606]}\end{array}$ & $\begin{array}{l}4.925 \\
{[77.974]}\end{array}$ & $\begin{array}{l}-9.814 \\
{[79.185]}\end{array}$ & $\begin{array}{l}-132.849 * * * \\
{[29.035]}\end{array}$ \\
\hline
\end{tabular}

The numbers in the bracket show the standard errors $*, * *, * * *$ Indicates $10 \%, 5 \%$ and $1 \%$ level of significance, respectively between sunshine duration and the number of total cases for different timeframes in all provinces of Turkey.

In Table 8, only lag 3 is significant and negatively correlated with COVID-19 cases. Table 9 shows that there is no relationship between sunshine duration and COVID-19 cases in all lags.
Table 10 summarizes the results of all models with all timeframes. That is, Table 10 shows that all weather parameters effects on COVID-19 cases with respect to lags.

We employed 6 different weather parameters. In lag 3, all parameters except for sunshine duration are negatively correlated with COVID-19 cases and significant. However, only 
Table 5 OLS results of wind speed models

Table 6 OLS results of air pressure models

Table 7 OLS Results of dew point models

\begin{tabular}{lllll}
\hline & Model 1 & Model 2 & Model 3 & Model 4 \\
\hline Density & $2.879 * * *$ & $2.894 * * *$ & $2.878^{* *}$ & $2.884 * * *$ \\
& {$[0.076]$} & {$[0.075]$} & {$[0.0762]$} & {$[0.0761]$} \\
Wind speed & -15.446 & & & \\
& {$[22.727]$} & & & \\
Wind speed_3 & & $-47.763^{*}$ & & \\
& & {$[27.095]$} & & \\
Wind speed_7 & & & -11.277 & 14.782 \\
& & & & {$[16.482]$} \\
Wind speed_14 & & & $-177.007 * * *$ & $-234.753 * * *$ \\
& & & {$[47.369]$} & {$[46.897]$} \\
\hline
\end{tabular}

The numbers in the square bracket show the standard errors

$*, * *, * * *$ Indicates $10 \%, 5 \%$ and $1 \%$ level of significance, respectively

\begin{tabular}{lllll}
\hline & Model 1 & Model 2 & Model 3 & Model 4 \\
\hline Density & $2.972 * * *$ & $2.972 * * *$ & $2.971^{* * *}$ & $2.968^{* * *}$ \\
& {$[0.070]$} & {$[0.070]$} & {$[0.070]$} & {$[0.071]$} \\
Pressure & $-1.768 * * * *$ & & & \\
& {$[.379]$} & & & \\
Pressure_3 & & $-1.791^{* * *}$ & & \\
Pressure_7 & & {$[.380]$} & $-1.735^{* * *}$ & \\
& & & {$[.377]$} & $-1.603 * * *$ \\
Pressure_14 & & & & {$[.364]$} \\
Constant & $1439.022^{* * *}$ & $1453.317 * * *$ & $1416.094 * * *$ & $1292.111^{* * *}$ \\
& {$[352.011]$} & {$[352.165]$} & {$[351.726]$} & {$[339.943]$} \\
\hline
\end{tabular}

The numbers in the square bracket show the standard errors

$*, * *, * * *$ Indicates $10 \%, 5 \%$ and $1 \%$ level of significance, respectively

\begin{tabular}{lllll}
\hline & Model 1 & Model 2 & Model 3 & Model 4 \\
\hline Density & $2.913 * * *$ & $2.956^{* * *}$ & $2.923 * * *$ & $2.896 * * *$ \\
& {$[0.068]$} & {$[0.069]$} & {$[0.069]$} & {$[0.071]$} \\
Dew point & $-38.263 * * *$ & & & \\
& {$[8.705]$} & & & \\
Dew point_3 & & $-39.994 * * *$ & & \\
Dew point_7 & & {$[8.544]$} & $-35.110^{* * *}$ & \\
Dew point_14 & & & {$[8.320]$} & $-15.661 * * *$ \\
& & & & {$[4.534]$} \\
Constant & -24.244 & -2.089 & -54.335 & $-230.007 * * *$ \\
& {$[46.731]$} & {$[48.550]$} & {$[42.267]$} & {$[26.860]$} \\
\hline
\end{tabular}

The numbers in the square bracket show the standard errors

$*, * *, * * *$ Indicates $10 \%, 5 \%$ and $1 \%$ level of significance, respectively 
Table 8 OLS Results of humidity models

\begin{tabular}{lllll}
\hline & Model 1 & Model 2 & Model 3 & Model 4 \\
\hline Density & $2.880^{* * *}$ & $2.908 * * *$ & $2.896 * * *$ & $2.877 * * *$ \\
& {$[0.076]$} & {$[0.075]$} & {$[0.076]$} & {$[0.076]$} \\
Humidity & -1.801 & & & \\
& {$[2.496]$} & & & \\
Humidity_3 & & $-6.056^{* *}$ & & \\
& & {$[2.728]$} & & \\
Humidity_7 & & & -3.557 & \\
Humidity_14 & & & {$[2.491]$} & \\
& & & & -0.438 \\
Constant & -58.509 & 294.428 & 60.104 & -167.294 \\
& {$[197.165]$} & {$[224.075]$} & {$[183.781]$} & {$[108.816]$} \\
\hline
\end{tabular}

The numbers in the square bracket show the standard errors

$*, * *, * * *$ Indicates $10 \%, 5 \%$ and $1 \%$ level of significance, respectively

3 parameters, temperature, air pressure and dew point are negatively correlated with COVID-19 cases and significant for lag 0 , lag 7 and lag 14 . Moreover, temperature, air pressure and dew point parameters are negative and significant in all timeframes.

\section{Discussion}

While some of our results are in line with the previous studies, some are different. Our findings show that COVID-19 cases have a positive and significant association with population density. Ahmadi et al. (2020) and Şahin (2020) also found same result which population density has significant effect to spread of COVID-19 cases. It is understood why
Table 10 Summary of all models

\begin{tabular}{lllll}
\hline Weather Parameters & Lag 0 & Lag 3 & Lag 7 & Lag 14 \\
\hline Temperature & - S & $-S$ & $-S$ & $-S$ \\
Wind speed & - & $-S$ & - & + \\
Air pressure & $-S$ & $-S$ & $-S$ & $-S$ \\
Dew point & $-S$ & $-S$ & $-S$ & $-S$ \\
Humidity & - & $-S$ & - & - \\
Sunshine duration & + & + & + & - \\
\hline
\end{tabular}

“-", "+" and "S" indicate that negative, positive and significant, respectively

policymakers decided to the social distance rule in public places (Zhang et al. 2020).

We also find that in lag 3, all parameters except for sunshine duration are negatively correlated with COVID-19 cases and significant. However, only 3 parameters, temperature, air pressure and dew point are negatively correlated with COVID-19 cases and significant for lag 0, lag 7 and lag 14. In addition, temperature, air pressure and dew point parameters are negative and significant in all timeframes.

It is observed that the number of COVID-19 cases decrease as temperature increases. Our results are in line with the studies of Adedokun et al. (2020) and Liu et al. (2020). Air pressure and dew point negatively associated with COVID-19 cases and significant. Our air pressure findings are consistent with Pani et al. (2020) but dew point results are not. We find that humidity has a negative relationship with the spread of COVID-19 which results are similar with result of Auler et al. (2020). Although sunshine duration is not a commonly used weather parameter to explain the spread of the COVID-19. It is not significant in our models.
Table 9 OLS Results of sunshine duration models

\begin{tabular}{lllll}
\hline & Model 1 & Model 2 & Model 3 & Model 4 \\
\hline Density & $2.885^{* * *}$ & 2.892 & $2.896^{* * *}$ & $2.877 * * *$ \\
& {$[0.076]$} & {$[0.075]$} & {$[0.076]$} & {$[0.076]$} \\
Sunshine duration & 5.313 & & & \\
& {$[8.001]$} & & & \\
Sunshine duration_3 & & 18.077 & & \\
& & {$[12.943]$} & 10.676 & \\
Sunshine duration_7 & & {$[7.423]$} & -5.152 \\
& & & & {$[6.505]$} \\
Sunshine dura- & & & $-239.009 * * *$ & - \\
tion_14 & & & {$[38.452]$} & $183.852^{* * *}$ \\
Constant & -218.227 & {$[32.662]$} & & {$[33.530]$} \\
\hline
\end{tabular}

The numbers in the square bracket show the standard errors

$*, * *, * * *$ Indicates $10 \%, 5 \%$ and $1 \%$ level of significance, respectively 


\section{Conclusion}

This paper mainly aims to contribute the existing literature by investigating the relationship between several weather variables for 4 different timeframes, population density and COVID-19 cases in Turkey. In addition to the previous studies, we employed cross section model to understand how COVID-19 cases are affected from several weather parameters in 4 different lags for 81 provinces of Turkey.

Our findings show that all of the parameters except for sunshine duration are negatively correlated with COVID19 cases and significant in lag 3. But only 3 parameters, temperature, air pressure and dew point are negatively correlated with COVID-19 cases and significant for lag 0, lag 7 and lag 14. At the same time, temperature, air pressure and dew point parameters are negative and significant in all timeframes. Active precautions should be taken to curb the spread of COVID-19. There are some different and significant factors that may affect the transmission of COVID19. Social activities such as weddings, funerals and entertainment, which are important cultures of Turkish society, accelerate the spread of the virus. Therefore, policymakers have banned and took action, since the virus was outbreak. In many provinces, it is compulsory to wear a mask when people leave the house. Ensuring social distance is also an important factor to prevent the spread of COVID-19.

On the other hand, policymakers should consider that these kinds of studies demonstrate preliminary works and they have several limitations. We encourage researchers to revisit this study in recent months, considering wider data for 81 provinces of Turkey by a deeper understanding of the relationship between weather parameters and the spread of COVID-19.

Funding This research did not receive any specific grant from funding agencies in the public, commercial, or not-for-profit sectors.

Data availability Not applicable.

Code availability Not applicable.

\section{Compliance with ethical standards}

Conflict of interest The authors declare that they have no known competing financial interests or personal relationships that could have appeared to influence the work reported in this paper.

\section{References}

Adedokun KA, Olarinmoye AO, Mustapha JO, Kamorudeen RT (2020) A close look at the biology of SARS-CoV-2, and the potential influence of weather conditions and seasons on COVID-19 case spread. Infect Dis Poverty 9(1):77. https://doi.org/10.1186/s4024 9-020-00688-1

Ahmadi M, Sharifi A, Dorosti S, Jafarzadeh Ghoushchi S, Ghanbari $\mathrm{N}$ (2020) Investigation of effective climatology parameters on COVID-19 outbreak in Iran. Sci Total Environ 729:138705. https ://doi.org/10.1016/j.scitotenv.2020.138705

Angrist JD, Pischke JS (2009) Mostly harmless econometrics: an empiricist's companion. Mostly Harmless Econom. https://doi. org/10.1111/j.1475-4932.2011.00742.x

Auler AC, Cássaro FAM, da Silva VO, Pires LF (2020) Evidence that high temperatures and intermediate relative humidity might favor the spread of COVID-19 in tropical climate: a case study for the most affected Brazilian cities. Sci Total Environ 729:139090. https ://doi.org/10.1016/j.scitotenv.2020.139090

Bashir MF, Ma B, Bilal A, Komal B, Bashir MA, Tan D, Bashir M (2020) Correlation between climate indicators and COVID-19 pandemic in New York, USA. Sci Tot Environ 728:138835. https ://doi.org/10.1016/j.scitotenv.2020.138835

Gupta A, Pradhan B, Maulud KNA (2020a) Estimating the impact of daily weather on the temporal pattern of COVID-19 outbreak in India. Earth Syst Environ 4(3):523-534. https://doi.org/10.1007/ s41748-020-00179-1

Gupta S, Raghuwanshi GS, Chanda A (2020b) Effect of weather on COVID-19 spread in the US: a prediction model for India in 2020. Sci Total Environ 728:138860. https://doi.org/10.1016/j. scitotenv.2020.138860

Hewings-Martin Y (2020) How do SARS and MERS compare with COVID-19? Med News Today. https://www.medicalnewstoda y.com/articles/how-do-sars-and-mers-compare-with-covid-19

Iqbal N, Fareed Z, Shahzad F, He X, Shahzad U, Lina M (2020) The nexus between COVID-19, temperature and exchange rate in Wuhan city: new findings from partial and multiple wavelet coherence. Sci Total Environ 729:138916. https://doi.org/10.1016/j. scitotenv.2020.138916

Johns Hopkins University (2020) Coronavirus resource center. Johns Hopkins University, Baltimore

Lauer SA, Grantz KH, Bi Q, Jones FK, Zheng Q, Meredith HR, Azman AS, Reich NG, Lessler J (2020) The incubation period of coronavirus disease 2019 (COVID-19) from publicly reported confirmed cases: estimation and application. Ann Intern Med 172(9):577582. https://doi.org/10.7326/M20-0504

Li H, Xu X-L, Dai D-W, Huang Z-Y, Ma Z, Guan Y-J (2020a) Air pollution and temperature are associated with increased COVID-19 incidence:a time series study. Int J Infect Dis 97:278-282. https ://doi.org/10.1016/j.ijid.2020.05.076

Li W, Thomas R, El-Askary H, Piechota T, Struppa D, Abdel Ghaffar KA (2020b) Investigating the significance of aerosols in determining the coronavirus fatality rate among three European countries. Earth Syst Environ 4(3):513-522. https://doi.org/10.1007/s4174 8-020-00176-4

Liu J, Zhou J, Yao J, Zhang X, Li L, Xu X, He X, Wang B, Fu S, Niu T, Yan J, Shi Y, Ren X, Niu J, Zhu W, Li S, Luo B, Zhang K (2020) Impact of meteorological factors on the COVID-19 transmission: a multi-city study in China. Sci Total Environ 726:138513. https ://doi.org/10.1016/j.scitotenv.2020.138513

Ma Y, Zhao Y, Liu J, He X, Wang B, Fu S, Yan J, Niu J, Zhou J, Luo B (2020) Effects of temperature variation and humidity on the death of COVID-19 in Wuhan, China. Sci Total Environ 724:138226. https://doi.org/10.1016/j.scitotenv.2020.138226

Menebo MM (2020) Temperature and precipitation associate with Covid-19 new daily cases: A correlation study between weather and Covid-19 pandemic in Oslo, Norway. Sci Total Environ 737:139659. https://doi.org/10.1016/j.scitotenv.2020.139659

Pani SK, Lin N-H, RavindraBabu S (2020) Association of COVID19 pandemic with meteorological parameters over Singapore. 
Sci Total Environ 740:140112. https://doi.org/10.1016/j.scito tenv.2020.140112

Pramanik M, Udmale P, Bisht P, Chowdhury K, Szabo S, Pal I (2020) Climatic factors influence the spread of COVID-19 in Russia. Int J Environ Health Res. https://doi.org/10.1080/09603 123.2020.1793921

Rohrer M, Flahault A, Stoffel M (2020) Peaks of fine particulate matter may modulate the spreading and virulence of COVID-19. Earth Syst Environ. https://doi.org/10.1007/s41748-020-00184-4

Rosario DKA, Mutz YS, Bernardes PC, Conte-Junior CA (2020) Relationship between COVID-19 and weather: Case study in a tropical country. Int J Hyg Environ Health 229:113587. https://doi. org/10.1016/j.ijheh.2020.113587

Runkle JD, Sugg MM, Leeper RD, Rao Y, Matthews JL, Rennie JJ (2020) Short-term effects of specific humidity and temperature on COVID-19 morbidity in select US cities. Sci Total Environ 740:140093. https://doi.org/10.1016/j.scitotenv.2020.140093

Şahin M (2020) Impact of weather on COVID-19 pandemic in Turkey. Sci Total Environ 728:138810. https://doi.org/10.1016/j.scito tenv.2020.138810

Shi P, Dong Y, Yan H, Zhao C, Li X, Liu W, He M, Tang S, Xi S (2020) Impact of temperature on the dynamics of the COVID-19 outbreak in China. Sci Total Environ 728:138890. https://doi.org/10.1016/j. scitotenv.2020.138890

Tosepu R, Gunawan J, Effendy DS, Ahmad LOAI, Lestari H, Bahar H, Asfian P (2020) Correlation between weather and Covid-19 pandemic in Jakarta, Indonesia. Sci Tot Environ 725:138436. https:// doi.org/10.1016/j.scitotenv.2020.138436

WHO (2019a) Middle East respiratory syndrome coronavirus (MERSCoV). WHO, Geneva

WHO (2019b) Pneumonia of unknown cause China. World Health Organization, Geneva

WHO (2020) SARS (Severe Acute Respiratory Syndrome). WHO, Geneva

Wu Y, Jing W, Liu J, Ma Q, Yuan J, Wang Y, Du M, Liu M (2020) Effects of temperature and humidity on the daily new cases and new deaths of COVID-19 in 166 countries. Sci Total Environ 729:139051. https://doi.org/10.1016/j.scitotenv.2020.139051

Zhang J, Litvinova M, Liang Y, Wang Y, Wang W, Zhao S, Wu Q, Merler S, Viboud C, Vespignani A, Ajelli M, Yu H (2020) Changes in contact patterns shape the dynamics of the COVID-19 outbreak in China. Science 368(6498):1481-1486. https://doi.org/10.1126/ science.abb8001 